\title{
Deteksi Suhu Ruang Server dan Penggerak Kipas Berbasis Arduino Uno Dengan Report SMS
}

\author{
Jaenal Arifin ${ }^{1}$, Herryawan $\mathrm{P}^{2}$, Bukti Gultom ${ }^{3}$ \\ Program Studi S1 Teknik Elektro ${ }^{1,2}$, Program Studi D3 Teknik Telekomunikasi ${ }^{3}$ \\ Fakultas Telekomunikasi \& Elektro, Institut Teknologi Telkom Purwokerto \\ Jl. D.I Panjaitan No.128 Purwokerto 53147 Telp 0281-641629 \\ Jaetoga@ittelkom-pwt.ac.id ${ }^{1}$, \\ herryawan@ittelkom-pwt.ac.id ${ }^{2}$ \\ 14201008@ st3telkom.ac.id ${ }^{3}$
}

Intisari---Suhu merupakan salah satu hal yang sangat berpengaruh terhadap kinerja perangkat keras khususnya ruang server. Ruang server adalah ruangan yang dapat digunakan untuk menyimpan data, perangkat jaringan dan operasional sistem. Deteksi suhu ruang server dirancang menggunakan 4 (empat) sensor LM35 yang berfungsi mendeteksi suhu didalam ruang server. Nilai suhu rata-rata ruang server ditampilkan pada LCD. Apabila suhu diruang server mengalami overheat, maka module GSM SIM900 akan mengirimkan informasi suhu ruang server ke administrator ruang server melalui sms. Perangkat deteksi suhu ruang server terdiri dari rangkaian catu daya, 4 (empat) sensor LM35, Arduino UNO, LCD, relay, kipas angin, module GSM dan handphone. Perangkat ini dapat monitoring suhu ruang server dan dapat memberikan informasi apabila suhu ruangan naik. Kipas angin berfungsi menormalkan suhu panas ruang server apabila suhu ruangan naik. Perangkat deteksi suhu pada ruang server ini mampu membantu administrator untuk memonitoring suhu ruang server dari jarak jauh dengan report SMS.

Kata kunci--- Arduino Uno, Ruang Server, Sensor Suhu, GSM SIM900

Abstract---Temperature has a very influential impact on the performance of hardware, especially the one which is kept in a server room. The server room is a room that can be used to store data, network devices and operation systems. The detection system of server room's temperature is designed by using 4 (four) LM35 sensors which functions is to detect the temperature in the server room. The value of average temperatures in the server room is displayed on the LCD. If the temperature in the server room reachs an overheated degree, the GSM SIM900 module will send the information about the temperature situation in the server room to the server room's administrator by using an SMS. The server room's temperature detection device consists of power supply circuits, 4 (four) LM35 sensors, Arduino UNO, LCD, relay, fan, GSM module and mobile phone. This device can monitor the temperature of the server room and can provide information when the room temperature rises. The fan's function is to normalize the hot temperature in the server room when the room's temperature rises above a certain degree. Temperature's detection device in the server room is capable to help administrators to monitor the temperature of the server room remotely using an SMS report.

Keywords--- Arduino Uno, Server Space, Temperature Sensors, GSM SIM900 


\section{PENDAHULUAN}

Ruang server merupakan ruang yang berisi instalasi komputer server atau tempat perangkat utama komputer server [1]. Suhu ruang server merupakan ruangan yang suhunya harus selalu dimonitoring. Hal tersebut penting karena server adalah pusat data yang ada didalam sebuah sistem, karena data-data tersebut bisa saja memiliki nilai yang tinggi atau mempunyai nilai yang penting. Sistem pemantauan suhu ruang server yang ada membutuhkan peran administrator, karena administrator harus berada pada lokasi dimana sistem tersebut bekerja. Hal ini dapat menimbulkan ketidakefisienan waktu dan tempat. Membuat pengaturan dan pengontrolan seluruh ruang server menjadi kurang efektif. Penelitian dengan judul deteksi suhu ruang server dan penggerak kipas berbasis Arduino Uno dengan report sms mengusulkan pemantauan suhu diruang server dapat dilakukan. Suhu ruang server dapat diketahui tanpa administrator ada dilokasi server. Report pemantau suhu dengan melalui media informasi sms.

Pada penelitian lain terkait suhu bisa diaplikasikan untuk monitoring suhu pada perangkat telekomunikasi [2]. Penelitiannya yang memberikan manfaat agar suatu perangkat telekomunikasi dapat tetap terjaga suhunya sesuai dengan cara kerja dan fungsinya. Alat pendingin perangkat telekomunikasi berada di dalam shelter BTS dengan sumber listrik arus searah (DC) dan bekerja secara otomatis dengan menggunakan Arduino Uno. Aplikasi pemantau suhu juga dapat dilakukan dengan sensor HTU21D [3]. Tidak harus menggunakan sensor LM35 dan tidak mesti berbasis Arduino Uno.

Aplikasi pemantau suhu juga dapat dilakukan dengan sensor HTU21D. Tidak harus menggunakan sensor LM35. Dengan menggunakan Nuvoton NUC140VE3CN dapat dimanfaatkan untuk mengolah data suhu dan kelembaban udara dari sensor HTU21D, data suhu ditampilkan pada LCD 128x64 dan dikirimkan melalui PC dengan bantuan komunikasi serial (via modul FTDI232RL).

\section{DASAR TEORI}

\section{A. Short Message Service (SMS)}

Aplikasi yang berfungsi sebagai pengolahan pesan, dimana SMS ini menangani banyak pertukaran SMS dalam sebuah perangkat lunak. Prinsip kerjanya adalah storeand forward, sehingga pesan yang masuk akan ditampung tanpa melihat status keberadaan tujuan. Jika nomor tidak terjangkau SMS akan mengulanginya sampai terkirim dalam batas waktu yang ditentukan [4]. Adapun arsitektur dari Short Message Service (SMS) adalah :

1.Terminal Equipment (TE) adalah perangkat output dari Mobile Station (MS), menawarkan layanan ke pengguna.

2. Mobile Station (MS) merupakan perangkat yang digunakan oleh pelanggan untuk melakukan komunikasi. Terdiri atas :

- Mobile Equipment (ME) merupakan perangkat yang ada pada pengguna sebagai terminal tranceiver untuk berkomunikasi dengan perangkat lain.

- Subcriber Identity Module (SIM) merupakan perangkat yang berisi seluruh informasi pelanggan dan informasi pelayanan.

- Base Station System (BSS) terdiri atas :

- Base Tranceiver Station (BTS) adalah perangkat GSM yang berhubungan langsung dengan MS dan berfungsi sebagai pengirim dan penerima sinyal.

- Base Station Controller (BSC) adalah perangkat yang mengontrol BTS yang berada dibawahnya dan sebagai penghubung ke MSC.

- Network Sub System (NSS) terdiri atas :

- Home Location Register (HLR) berfungsi sebagai sebagai database untuk menyimpan semua data dan informasi pelanggan secara permanen.

- Mobile Switching Center (MSC) merupakan network element central pada jaringan GSM, sebagai inti dari jaringan seluler dimana MSC berperan sebagai interkoneksi [4].

Arduino Uno merupakan rangkian single board mikropngendali yang dibuat untuk keperluan proyek elektronika supaya lebih mudah diwujudkan [5]. Berikut single board dari Arduino Uno. 


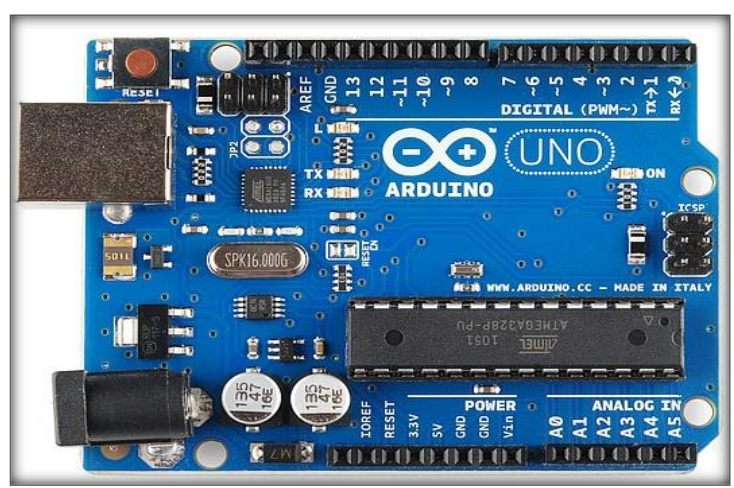

Gbr.1 Single board Arduino Uno [5].

\section{B. Bagian-bagian dari Arduino Uno yaitu: \\ - 14 pin input/output digital (0-13)}

Berfungsi sebagai input atau output, dapat diatur oleh program. Khusus untuk 6 buah pin $3,5,6,9,10$ dan 11 , dapat juga berfungsi sebagai pin analog output dimana tegangan output dapat diatur. Nilai sebuah pin output analog dapat diprogram antara $0-255$, dimana hal itu mewakili nilai tegangan $0-$ $5 \mathrm{~V}$.

\section{- USB}

Berfungsi untuk memuat program dari komputer ke dalam papan, komunikasi serial antara papan dan komputer, dan memberi daya listrik kepada papan Arduino.

\section{- Sambungan SV1}

Sambungan atau jumper untuk memilih sumber daya papan, apakah dari sumber eksternal atau menggunakan USB. Sambungan ini tidak diperlukan lagi pada papan Arduino.

\section{- Quartz Crystal Oscillator (Q1-kristal)}

Jika mikrokontroler dianggap sebagai sebuah otak, maka kristal adalah jantung-nya karena komponen ini menghasilkan detak-detak yang dikirim kepada mikrokontroler agar melakukan sebuah operasi untuk setiap detaknya. Kristal ini dipilih yang berdetak 16 juta kali per detik (16MHz).

\section{- Tombol Reset S1}

Untuk me-reset papan sehingga program akan mulai lagi dari awal. Perhatikan bahwa tombol reset ini bukan untuk menghapus program atau mengosongkan mikrokontroler.
- In-Circuit Serial Programming (ICSP)

Port ICSP memungkinkan pengguna untuk memprogram mikrokontroler secara langsung, tanpa melalui bootloader.Umumnya pengguna Arduino tidak melakukan ini sehingga ICSP tidak terlalu dipakai walaupun disediakan.

- IC 1-Mikrokontroler Atmega

Komponen utama dari papan Arduino, di dalamnya terdapat CPU, ROM dan RAM.

3. X1-Sumber Daya Eksternal

Jika hendak disuplai dengan sumber daya eksternal, papan Arduino dapat diberikan tegangan DC antara 9-12V.

- 6 pin input analog (0-5)

Pin ini sangat berguna untuk membaca tegangan yang dihasilkan oleh sensor analog, seperti sensor suhu. Program dapat membaca nilai sebuah pin input antara $0-1023$, dimana hal itu mewakili nilai tegangan $0-5 \mathrm{~V}$ [5].

Mikropengendali merupakan sebuah perangkat pengendali yang dapat digunakan untuk kepentingan kontrol, instrumentasi, robotika atau lainnya [6].

Karakteristik dari mikrokontroler AVR Atmega328 yaitu :

$>$ Universal Asynchronous

Receiver/Transmitter (UART) adalah antar muka yang digunakan untuk komunikasi serial seperti pada RS-232, RS-422 dan RS-485.

$>$ 2KB RAM pada memori kerja bersifat hilang saat daya dimatikan (volatile), digunakan oleh variabel-variabel di dalam program.

$>$ 32KB RAM flash memori bersifat nonvolatile, digunakan untuk menyimpan program yang dimuat dari komputer. Selain program, flash memori juga menyimpan bootloader. Bootloader adalah program inisiasi yang ukurannya kecil, dijalankan oleh CPU saat daya dihidupkan. Setelah bootloader selesai dijalankan, berikutnya program di dalam RAM akan dieksekusi.

$>1 \mathrm{~KB}$ EEPROM bersifat non-volatile, digunakan untuk menyimpan data yang tidak boleh hilang saat daya dimatikan. Tidak digunakan pada papan Arduino. 
$>$ Central Processing Unit (CPU), bagian dari mikrokontroler untuk menjalankan setiap instruksi dari program.

$>$ Port input/output, pin-pin untuk menerima data (input) digital atau analog, dan mengeluarkan data (output) digital atau analog.

\section{Sensor LM35}

Sensor suhu yang dapat diaplikasikan pada bidang elektronika. Sensor tersebut memiliki fungsi untuk mengubah besaran suhu menjadi besaran listrik dalam bentuk tegangan $(\mathrm{mV})$. Sensor LM35 yang dipakai dalam penelitian ini berupa sensor dalam bentuk komponen elektronika yang diproduksi oleh National Semiconductor. Sensor LM35 memiliki keakuratan tinggi dan kemudahan perancangan jika dibandingkan dengan sensor suhu yang lain. Sensor LM35 juga mempunyai keluaran impedansi yang rendah dan linieritas yang tinggi sehingga dapat dengan mudah dihubungkan dengan rangkaian kendali khusus serta tidak memerlukan penyetelan lanjutan [7]. Berikut bentuk fisik dari sensor

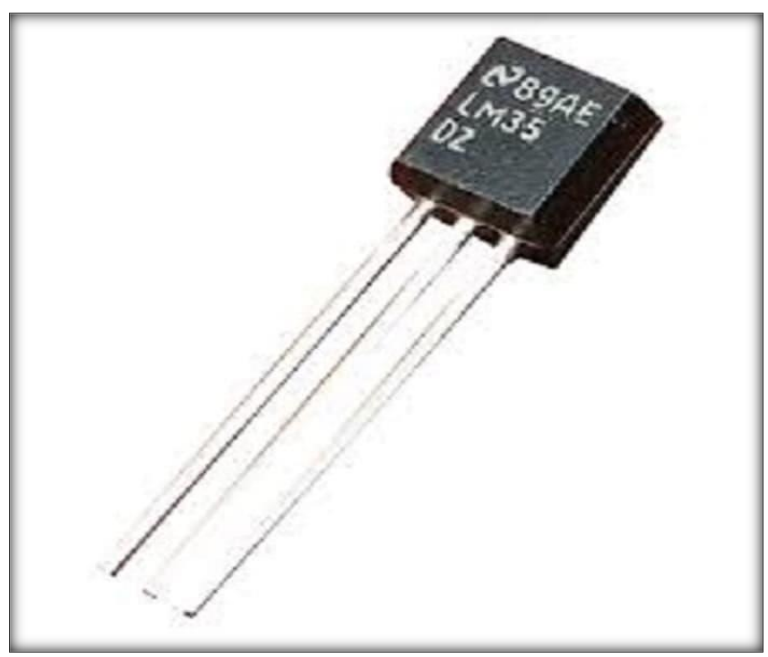

Gbr.2 Sensor LM35

Karakteristik dari sensor LM3 yaitu:

- Memiliki sensitivitas suhu, dengan faktor skala linier antara tegangan dan suhu 10 $\mathrm{mV} /{ }^{\circ} \mathrm{C}$, sehingga dapat dikalibrasi langsung dalam Celcius.

- Memiliki ketepatan atau akurasi kalibrasi yaitu $0,5^{\circ} \mathrm{C}$ pada suhu $25^{\circ} \mathrm{C}$.

- Memiliki jangkauan maksimal operasi suhu antara $-55^{\circ} \mathrm{C}$ sampai $150{ }^{\circ} \mathrm{C}$.
- Bekerja pada tegangan 4 sampai 30V.

- Memiliki arus rendah.

- Memiliki pemanasan sendiri yang rendah (low-heating) yaitu kurang dari $0,1^{\circ} \mathrm{C}$ pada udara diam.

- Memiliki impedansi keluaran yang rendah yaitu $0,1 \mathrm{~W}$ untuk beban $1 \mathrm{~mA}$.

- Memiliki ketidaklinieran hanya sekitar $\pm 1 / 4$ ${ }^{\circ} \mathrm{C}$.

\section{SIM 900}

Module Global System for Mobile Communication (GSM) SIM900 dapat digunakan untuk melakukan fungsi seperti halnya sebuah perangkat komunikasi yang mampu mengirimkan SMS maupun melakukan panggilan layaknya telepon konvensional pada umumnya [8].

Karakteristik dari module GSM SIM900 sebagai berikut :

- Sepenuhnya kompatibel dengan Arduino Uno dan Mega.

- Sambungan port serial gratis, port hardware serial port (D0 / D1) atau software serial. Port (D2 / D3) mengendalikannya.

- SIM900 semua pin breakout. Bukan hanya port UART dan port debug saja yang tata letak, tetapi juga semua pin pada module SIM900.

- Pasokan daya kapasitor super untuk RTC.

- EFCom tidak hanya bisa menggunakan tombol POWER/ON, tapi juga bisa menggunakan pin digital Arduino untuk menyalakannya ON dan RESET module SIM900.

- Quad-Band 850/900/1800/1900 MHz.

- Kelas multi-slot GPRS 10/8.

- Suhu operasi: $-40^{\circ} \mathrm{C}$ sampai $+85^{\circ} \mathrm{C}$.

- Dimensi: 68.33x53.09mm (dimensi yang sama dari papan utama Arduino).

\section{Liquid Crystal Display (LCD)}

Perangkat display yang paling umum dipasangkan ke pengendali, mengingat ukurannya yang kecil dan kemampuan menampilkan karakter atau grafik yang lebih baik dibandingkan tampilan 7 segment ataupun alphanumeric [9]. 
Rangkaian catu daya merupakan suatu rangkaian yang berfungsi untuk menyediakan daya [10]. Rangkaian ini menggunakan komponen utama yaitu transformator. Salah satu sifat transformator adalah mengubah nilai suatu tegangan. Pengubah tegangan yang banyak terdapat di pasaran adalah pengubah tegangan Alternating Current (AC) ke Direct Current (DC). Sedangkan untuk jenis yang lain jarang dijumpai dalam di pasaran. Seperti pengubah DC ke DC, dalam penggunaannya untuk mengubah tegangan DC ke DC dengan nilai tegangan yang berbeda. Misalnya, Jika mempunyai rangkaian dengan tegangan sumber $+5 \mathrm{~V}$, dapat dikembangkan dengan menggunakan pengubah DC ke DC untuk menghasilkan tegangan sumber $+15 \mathrm{~V}$. Sehingga mempunyai tegangan sumber untuk sistem tersebut $+5 \mathrm{~V}$ dan $+15 \mathrm{~V}$. Keluaran tegangan dari adaptor yang digunakan adalah dari $1.5 \mathrm{~V}, 3 \mathrm{~V}, 4.5 \mathrm{~V}, 6 \mathrm{~V}, 7.5 \mathrm{~V}, 9 \mathrm{~V}$ dan $12 \mathrm{~V}$, karena rangkaian membutuhkan tegangan $5 \mathrm{~V}$ maka harus memakai tegangan dari 6V-12V[11]. Relay merupakan salah satu komponen elektronika yang dapat berfungsi sebagai saklar.

Relay maupun kontaktor magnet memiliki kumparan (coil) yang apabila di aliri arus listrik DC maka besi sebagai inti dari kumparan akan menjadi magnet, sehingga batang bergerak yang sama sama terbuat dari besi akan di tarik sehingga lengket pada inti besi [12]. Hal ini mengakibatkan kontak Normaly Close (NC) akan berubah menjadi kontak Normally Open (NO). Pada relay terdiri dari 4 komponen dasar yaitu : Coil (Electromagnet), Armature, Switch Contact Point (Saklar) dan Spring.

Integrated Development Environment (IDE) dari Arduino tidak memiliki fitur-fitur canggih seperti debugger atau kode completion. IDE dari Arduino hanya dapat mengubah beberapa preferensi, dan sebagai aplikasi Java itu tidak sepenuhnya mengintegrasikan ke desktop atau mac [5]. Berikut fungsi-fungsi toolbar Arduino IDE :

1. Dengan tombol verifikasi dapat mengkompilasi program yang saat ini di editor.

2. Tombol new membuat program baru dengan mengosongkan isi dari jendela editor saat ini.
Sebelum hal itu terjadi, IDE memberikan kesempatan untuk menyimpan semua perubahan yang belum disimpan.

3. Dengan open dapat membuka program yang ada dari sistem file.

4. Tombol save menyimpan program saat ini.

5. Ketika mengklik tombol upload, IDE mengkompilasi saat ini program dan upload ke papan Arduino yang telah di pilih di IDE menu tools > serial port.

6. Arduino dapat berkomunikasi dengan komputer melalui koneksi serial. Mengklik tombol serial monitor membuka jendela serial monitor yang memungkinkan untuk melihat data yang dikirim oleh Arduino dan juga untuk mengirim data kembali.

7. Tombol stop menghentikan serial monitor

AT Command adalah program yang digunakan pada handphone atau GSM/CDMA modem untuk mengirimkan atau menerima SMS. Komputer maupun mikrokontroler dapat memberikan perintah AT Command melalui komunikasi data serial atau bluetooth. Antar perangkat telepon seluler dan GSM/CDMA modem bisa memiliki perintah AT Command yang berbeda-beda, namun biasanya mirip antara satu dengan yang lainnya[4]. Komunikasi serial merupakan salah satu standar komunikasi yang secara umum dapat digunakan oleh komputer maupun perangkat digital lainya. Komunikasi serial dapat juga digunakan untuk bertukar data dengan perangkat lain[13]. Terdapat dua metode pada komunikasi serial yaitu sinkron dan tidak sinkron. Pada komunikasi tak sinkron kecepatan transmisi harus sama antara pengirim dan penerima. Kecepatan transmisi (baud rate) dapat dipilih bebas dalam rentang tertentu, baud rate yang umum dipakai adalah 110, 300, 600, 2400, 9600, 19200 dan 115200 . dalam komunikasi serial baudrate dari kedua alat yang berhubungan harus diatur pada kecepatan yang sama.

\section{METODE PENELITIAN}

Berikut metode yang digunakan pada penelitian ini, yaitu meliputi perancangan sistem secara keseluruhan. 
A. Blok Diagram Sistem

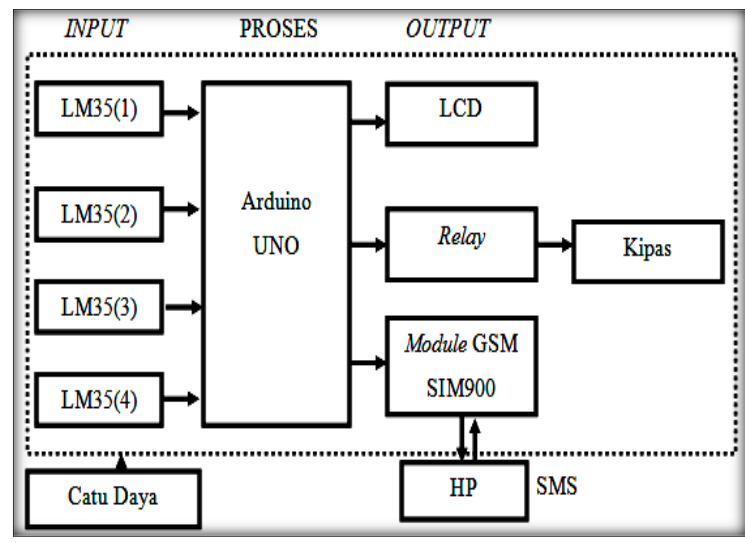

Gbr. 3 Blok Diagram Sistem

Berikut penjelasan dari bagian-bagian pada blok diagram tersebut.

- Catu Daya

Catu daya pada rangkaian tersebut digunakan untuk mencatu seluruh rangkaian. Catu daya menggunakan trafo step down sebagai penurun tegangan yang mengubah sumber tegangan $\mathrm{AC}$ $220 \mathrm{~V}$ menjadi tegangan DC $9 \mathrm{~V}$.

- Sensor LM35

Sensor LM35 berfungsi untuk mendeteksi suhu ruang server dengan cara mengubah besaran suhu menjadi besaran listrik dalam bentuk tegangan.

- Arduino Uno

Arduino Uno berfungsi sebagai otak atau pengendali seluruh rangkaian dan menyimpan program yang digunakan dalam rangkaian tersebut. Arduino Uno tersebut memiliki 14 pin digital dan 6 pin analog.

- Liquid Crystal Display (LCD)

Liquid Crystal Display (LCD) digunakan untuk menampilkan data yang yang sudah diproses.

- Relay

Relay digunakan sebagai saklar untuk menyalakan dan menghidupkan kipas.

- Kipas

Kipas digunakan untuk menurunkan suhu ruang server apabila suhu sudah overheat.

- Module GSM SIM900

Module GSM SIM900 sebagai media komunikasi serial antara Arduino Uno dengan Smartphone.

- HP

Handphone (HP) tersebut digunakan untuk mengirim dan menerima informasi berupa SMS.

\section{B. Perancangan Perangkat Lunak}

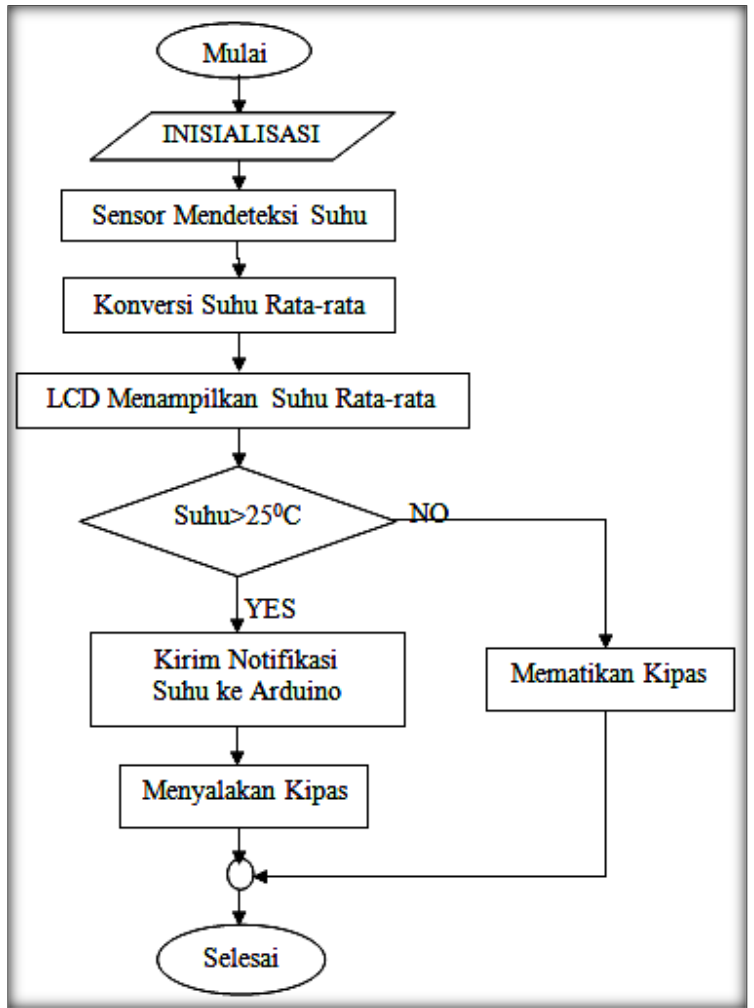

Gbr. 4 Flowchat Program Cara Kerja Alat

Berikut keterangan flowchart program cara kerja alat :

1. Mulai : Memulai Program.

2. Inisialisasi Program : yang bermaksud untuk menentukan pin input atau output yang akan digunakan dalam merancang alat.

3. Sensor Mendeteksi Suhu : sensor LM35 akan mendeteksi suhu ruang server.

4. Konversi Suhu Rata-rata : sensor LM35 terdapat pengkonversian analog ke nilai suhu digital dalam satuan Celcius.

5. LCD Menampilkan Suhu Rata-rata : suhu yang akan ditampilkan dalam satuan Celcius di Liquid Crystal Display (LCD).

6. Suhu >250C: artinya suhu rata-rata ruang server lebih besar dari 250Celcius.

7. Kirim Notifikasi Suhu ke Arduino

8. Menyalakan Kipas

9. Mematikan Kipas

\section{IV.HASIL PENELITIAN}

Hasil yang digunakan pada penelitian ini meliputi pengujian catu daya, pengujian sensor LM35, pengujian LCD, pengujian relay kipas, pengujian module GSM SIM900, dan pengujian keseluruhan. Hasil-hasil yang didapatkan 
adalah berikut ini :

\section{A. Pengujian Catu Daya}

Untuk men-supplay tegangan pada mikrokontroler dan komponen lainnya diperlukan tegangan sebesar $9 \mathrm{~V}$, oleh sebab itu digunkan rangkaian IC regulator 7809 untuk menstabilkan tegangan menjadi 9V. Tegangan keluaran sebesar $9 \mathrm{~V}$ berlaku untuk semua mikrokontroler yang dipakai pada prototype ini. Output DC, hasil yang didapatkan 8.99 VDC. Hasil output tersebut didapatkan setelah melewati ic regulator 7809, maka tegangan dapat diturunkan menjadi sekitar 9 VDC. Sesuai dengan hasil pengujian tiap bagian rangkaian catu daya, berikut hasil pengujian catu daya.

Tabel 1. Hasil Pengujian Catu Daya

\begin{tabular}{|c|c|c|c|}
\hline $\begin{array}{c}\text { Datasheet } \\
\text { (a) }\end{array}$ & $\begin{array}{c}\text { Hasil } \\
\text { Pengukuran } \\
\text { (b) }\end{array}$ & $\begin{array}{c}\text { Error } \\
(\mathrm{a}-\mathrm{b})\end{array}$ & $\begin{array}{c}\text { Presentase Error } \\
(\%)\end{array}$ \\
\hline $9=\frac{\mathrm{a}-\mathrm{b}}{\mathrm{a}} \times 100 \%$ \\
\hline $\mathrm{V}$ & $8.99 \mathrm{~V}$ & $0.01 \mathrm{~V}$ & $1 \%$ \\
\hline
\end{tabular}

Pada tabel 1. dapat dijelaskan bahwa terdapat dua hasil pengujian tegangan pada tiap bagian catu daya yaitu pengujian tegangan sekunder trafo, dan pengujian hasil akhir atau output yang dimana perubahan terjadi setelah melewat IC regulator 7089. Pada catu daya persentase error $1 \%$ masih bisa berfungsi untuk digunakan.

\section{B. Pengujian Sensor LM35}

Pengujian pada sensor LM35 ini yaitu tegangan keluaran yang akan diukur. Secara teori tegangan masukan ini yaitu $5 \mathrm{~V}$. Pengujian sensor LM35 dilakukan untuk mengetahui nilai suhu ruang server tersebut. Karena menggunakan tegangan referensi 5V, maka setiap kenaikan 1 derajat Celcius bisa dihitung dengan rumus :

$$
1^{0} \mathrm{C}=10 \mathrm{mV}
$$

Ruang server digunakan untuk pengukuran pengujian pada prototype dengan pengambilan data. Data yang diperoleh dari pengujian ini sebanyak 10 data.
Tabel 2. Perbandingan Tegangan dan Data Digital Sensor LM35.

\begin{tabular}{|c|c|c|c|c|c|c|c|c|}
\hline No & $\begin{array}{c}\text { Acuan } \\
\left({ }^{\circ} \mathrm{C}\right)\end{array}$ & $\begin{array}{c}\text { Sensor } \\
\left({ }^{\circ} \mathrm{C}\right)\end{array}$ & $\begin{array}{c}\text { Sensor } \\
\left({ }^{\circ} \mathrm{C}\right)\end{array}$ & $\begin{array}{c}\text { Sensor } \\
\left({ }^{\circ} \mathrm{C}\right)\end{array}$ & $\begin{array}{c}\text { Sensor } \\
\left({ }^{\circ} \mathrm{C}\right)\end{array}$ & $\begin{array}{c}\text { Suhu Rata-rata } \\
\left({ }^{\circ} \mathrm{C}\right)\end{array}$ & $\begin{array}{c}\text { Tegangan } \\
(\mathrm{mV})\end{array}$ & $\begin{array}{c}\text { Data } \\
\text { Digital }\end{array}$ \\
\hline 1 & 1 & 2 & 3 & 4 & $\frac{1+2+3+4}{4}$ & $1^{\circ} \mathrm{C}=10$ & \\
2 & 20 & 14.32 & 15.79 & 22.62 & 27.62 & 20.09 & 200.9 & 11001000 \\
3 & 21 & 21.81 & 22.30 & 22.79 & 22.79 & 22.42 & 224.2 & 11100000 \\
4 & 22 & 22.79 & 23.76 & 22.76 & 23.76 & 23.27 & 232.7 & 11101000 \\
5 & 23 & 22.30 & 22.79 & 23.27 & 22.79 & 22.79 & 227.9 & 11100011 \\
6 & 24 & 23.35 & 23.56 & 24.05 & 24.50 & 23.82 & 238.2 & 11101110 \\
7 & 25 & 26.05 & 24.74 & 25.36 & 25.41 & 25.39 & 253.9 & 11111101 \\
8 & 26 & 26.06 & 27.04 & 27.04 & 27.04 & 26,79 & 267.9 & 100001011 \\
9 & 27 & 27.04 & 27.53 & 27.53 & 27.53 & 27.41 & 274.1 & 100010010 \\
10 & 28 & 28.02 & 28.50 & 28.50 & 28.50 & 28.38 & 283.8 & 100011011 \\
\hline
\end{tabular}

Dari Jika Vref diberi tegangan 5 V (5000 $\mathrm{mV}$ ). Dan LM35 tidak mengeluarkan tegangan, maka $0 * 1024 / 5000=0$. Jika LM35 mengeluarkan tegangan sebesar $1 \mathrm{mV}$, maka akan mengeluarkan angka digital: $1 * 1024$ / $5000=0.2048$. Jika LM35 mengeluarkan tegangan sebesar $10 \mathrm{mV}$, maka uC akan mengeluarkan angka digital : $10 * 1024$ / 5000 $=2.048$.

\section{$V L M 35=S u h u * 10 m V$}

Dari Tabel 2 dapat disimpulkan tegangan ratarata $(\mathrm{mVrata}-\mathrm{rata})=239.81 \mathrm{mV}$. Hasil tersebut didapat dari jumlah tegangan dibagi 10 .

Tabel 3. Hasil Pengujian Sensor LM35

\begin{tabular}{|c|c|c|c|c|c|c|c|c|}
\hline \multirow[b]{2}{*}{ No } & \multicolumn{7}{|c|}{$\operatorname{Suhu}\left({ }^{\circ} \mathrm{C}\right)$} & \multirow[b]{2}{*}{$\begin{array}{c}\text { Error } \\
c=\frac{a-b}{a} \times 10046\end{array}$} \\
\hline & $\begin{array}{c}\text { Acusn } \\
\mathrm{a}\end{array}$ & $\begin{array}{c}\text { Sensor } \\
1\end{array}$ & $\begin{array}{c}\text { Sensor } \\
2\end{array}$ & $\begin{array}{c}\text { Sensor } \\
3\end{array}$ & $\begin{array}{c}\text { Sensor } \\
4\end{array}$ & $\begin{array}{c}\begin{array}{c}\text { Rata-Rata } \\
1+2+3+4\end{array} \\
4 \\
b\end{array}$ & $\begin{array}{c}\text { Selisih } \\
(a-b)\end{array}$ & \\
\hline 1 & 19 & 18.23 & 19.69 & 19.20 & 20.67 & 19.45 & 0.45 & 2.3 \\
\hline 2 & 20 & 14.32 & 15.79 & 22.62 & 27.62 & 20.09 & 0.09 & 0.4 \\
\hline 3 & 21 & 21.81 & 22.30 & 22.79 & 22.79 & 22.42 & 1.42 & 6.7 \\
\hline 4 & 22 & 22.79 & 23.76 & 22.76 & 23.76 & 23.27 & 1.27 & 5.7 \\
\hline 5 & 23 & 22.30 & 22.79 & 23.27 & 22.79 & 22.79 & 0.21 & 0.9 \\
\hline 6 & 24 & 23.35 & 23.56 & 24.05 & 24.50 & 23.82 & 0.18 & 0.7 \\
\hline 7 & 25 & 26.05 & 24.74 & 25.36 & 25.41 & 25.39 & 0.39 & 1,5 \\
\hline 8 & 26 & 26.06 & 27.04 & 27.04 & 27.04 & 26,79 & 0.79 & 3.0 \\
\hline 9 & 27 & 27.04 & 27.53 & 27.53 & 27.53 & 27.41 & 0.41 & 1.5 \\
\hline 10 & 28 & 28.02 & 28.50 & 28.50 & 28.50 & 28.38 & 0.38 & 1.3 \\
\hline
\end{tabular}

Dari Tabel 3 dapat disimpulkan error rata- rata $($ Error rata-rata $)=2.4$ Hasil tersebut didapat dari jumlah error dibagi 10. 


\section{Pengujian LCD}

Pengujian pada tegangan LCD adalah tegangan keluaran yang akan diukur. Secara teori tegangan masukan ini yaitu $5 \mathrm{~V}$. Pengujian ini dilakukan untuk mengetahui apakah berfungsi untuk menampilkan 32 karakter (16 karakter di kolom 1 dan 16 karakter di kolom ke 2) sesuai dengan masukan.

Tabel 4. Pengujian LCD

\begin{tabular}{|c|c|c|c|}
\hline $\begin{array}{c}\text { Datasheet } \\
\text { (a) }\end{array}$ & $\begin{array}{c}\text { Hasil } \\
\text { Pengukuran }\end{array}$ & $\begin{array}{c}\text { Error } \\
(\mathrm{a}-\mathrm{b})\end{array}$ & $\begin{array}{c}\text { Presentase Error } \\
(\%)\end{array}$ \\
& (b) & & $\mathrm{C}=\frac{\mathrm{a}-\mathrm{b}}{\mathrm{a}} \times 100 \%$ \\
\hline $5 \mathrm{~V}$ & $4.74 \mathrm{~V}$ & $0.26 \mathrm{~V}$ & $5.2 \%$ \\
\hline
\end{tabular}

Pada saat pengujian LCD, memasukkan listing program ke dalam software Arduino IDE, kemudian pada bagian listing program tersebut, seperti :

\#include <Wire.h>

\#include <LiquidCrystal_I2C.h>

LiquidCrystal_I2C $1 c d(0 \times 27,2,1,0,4,5,6,7,3$, POSITIVE);

void $\operatorname{setup}()$

\{

lcd.begin $(16,2)$;

\}

void loop()

\{

lcd.setBacklight(HIGH);

lcd.setCursor $(0,0)$;

lcd.print("1234567890");

lcd.setBacklight(HIGH);

$\operatorname{delay}(1000)$;

\}

Berikut tampilan dari hasil pengujiannya LCD

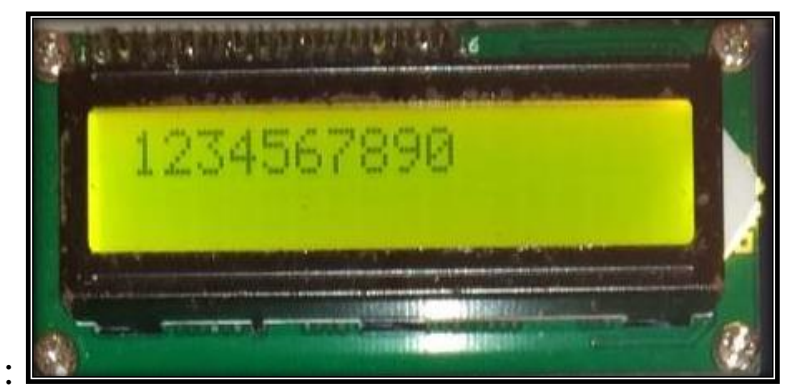

Gbr. 4 Pengujian LCD

\section{Pengujian Tegangan Relay}

Pengujian tegangan pada relay ini yaitu tegangan keluaran yang akan diukur.
Secara teori tegangan masukan ini yaitu $5 \mathrm{~V}$. Tegangan diukur menggunakan multimeter digital.

Tabel 5 Hasil Pengujian Tegangan Relay

\begin{tabular}{|c|c|c|}
\hline No & Kondisi (On/Off) & Vref \\
\hline 1 & On & $4.95 \mathrm{~V}$ \\
2 & Off & $0 \mathrm{~V}$ \\
\hline
\end{tabular}

\section{E. Pengujian Tegangan Module GSM SIM900}

Pengujian tegangan module GSM SIM900 dilakukan agar agar dapat mengetahui bahwa SMS dapat dikirim dari alat menuju HP dan dapat menerima SMS yang dikirim oleh pengguna HP. Tegangan yang dimiliki berasal dari catu daya trafo sebesar 5V. Dalam pengukuran tegangan yang didapatkan tidak berbeda jauh dengan $5 \mathrm{~V}$, tegangan diukur menggunakan multimeter digital. Pengukuran dilakukan dengan menghubungkan probe merah ke kaki positif dan probe hitam ke GND.

Tabel 4 hasil dari pengukuran menggunakan multimeter digital dengan nilai $4.94 \mathrm{~V}$.

Tabel 6.Tegangan Module GSM SIM900

\begin{tabular}{|c|c|c|c|}
\hline $\begin{array}{c}\text { Datasheet } \\
\text { (a) }\end{array}$ & $\begin{array}{c}\text { Hasil } \\
\text { Pengukuran } \\
\text { (b) }\end{array}$ & $\begin{array}{c}\text { Error } \\
\text { (a-b) }\end{array}$ & $\begin{array}{c}\text { Presentase Error } \\
(\%)\end{array}$ \\
\hline $5 \mathrm{~V}$ & $4.94 \mathrm{~V}$ & $0.06 \mathrm{~V}$ & $1 . \mathrm{b}$ \\
\hline
\end{tabular}

Pada pada pengujian module GSM SIM900 akan secara langsung memberitahu pengguna dengan melalui SMS berupa teks. Teks tersebut berupa 'Deteksi Suhu Ruang Server Suhu Ruangan Lebih Besar Dari 25 Celcius'.

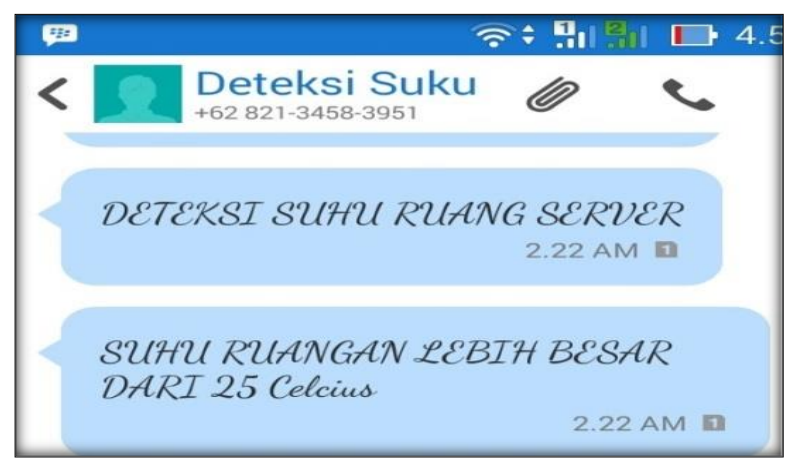

Gbr. 5 Informasi SMS 


\section{F. Pengujian Sistem Keseluruhan}

Pengujian sistem keseluruhan yang dilakukan ini untuk mengetahui apakah sistem dari alat yang telah dibuat dapat berjalan sesuai dengan yang diharapkan. Pengujian ini dilakukan dengan cara mendeteksi suhu dengan menggunakan sensor LM35. Dari pengujian keseluruhan ini menguji setiap komponen penting yang berfungsi. Pada setiap sensor LM35 mendeteksi suhu maka indikator yang berfungsi yaitu LCD, push button, kipas dan module GSM SIM900. Semua komponen ini berfungsi untuk mendeteksi suhu ruang server. Pengujian dan pengukuran yang dilakukan pada deteksi suhu ruang server dan penggerak kipas berbasis Arduino Uno dengan report SMS dapat berjalan dan berfungsi sesuai dengan yang diharapkan. Pengujian pada masing-masing alat ini meliputi kelayakan akan alat ini dan pengukuran fungsi dari setiap komponen yang digunakan tidak terkecuali tegangan yang diukur dengan multimeter digital. Pengukuran dan pengujian ini jika dibandingkan dengan datasheet yang ada. Hal ini berguna untuk mengetahui seberapa akuratnya sensor ini bekerja. Kemudian dibandingkan dan dihitung selisihnya, meskipun hasil dari teori dan juga praktik atau pengukuran tidak sama, akan tetapi selisih perbandingan yang didapatkan tidak berbeda terlalu jauh. Alat ini jika nantinya dapat diaplikasikan pada suatu hal yang sebenarnya atau di kenyataan, maka hal ini akan mempermudah administrator server untuk dapat mengetahui kondisi dari ruang server.

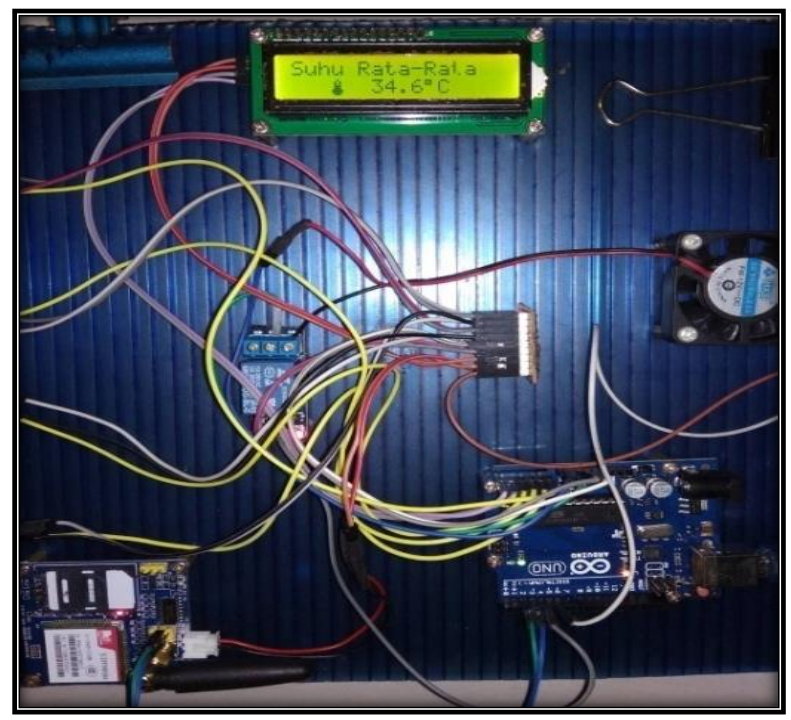

Gbr. 6 Pengujian Secara Keseluruhan
Prototype ini dilengkapi dengan LCD yang digunakan sebagai awal untuk mengetahui kondisi suhu. Apabila kondisi sistem mendeteksi suhu lebih besar /lebih kecil dari suhu rata-rata, maka ada pemberitahuan kepada administrator server melalui Short Message Service (SMS). Dari pengujian tersebut diperoleh saat pengiriman data dari module GSM SIM900 ke HP memiliki delay. Dan delay paling lama 20 detik. Kelebihan pada alat ini dapat monitoring suhu ruang server dengan kendali jarak jauh

\section{KESIMPULAN}

Berikut hasil kesimpulan setelah melakukan pengujian dan analisa pada sistem deteksi suhu ruang server :

1. Sistem deteksi suhu ruang server dirancang sesuai dengan apa yang diharapkan, pada sistem yang dibuat dapat melakukan pengiriman SMS menggunakan Module GSM SIM900, dengan berjalannya sistem ini maka administator dapat memonitoring suhu ruang server secara jarak jauh.

2. Hasil pengujian catu daya menghasilkan error sebesar $1 \%$.

3. Sistem deteksi suhu ruang server dan penggerak kipas dapat dinyalakan dan dimatikan melalui SMS.

4. Hasil pengujian module GSM SIM900 dapat mengirimkan pesan informasi suhu berupa teks.

\section{REFERENSI}

[1] A. Rahardjo, "Rancang Bangun Aplikasi Pengaturan Dan Pengendalian Suhu Ruang Server Berbasis Web Service Dan Sms Gateway," Institut Teknologi Sepuluh Nopember, 2011.

[2] I. E. Dewanti, J. Arifin, and D. Kurnianto, "Rancang Bangun Pendingin Perangkat Telekomunikasi Otomatis Berbasis Arduino Uno," pp. 18-24, 2013. [3] J. Arifin, A. H. Saptadi, and R. A. P. T. W, "Aplikasi Pemantau Suhu dan Kelembaban Udara Berbasis Nuvoton NUC140VE3CN dan Sensor HTU21D," vol. 9, no. 4, pp. 422-428, 2017.

[4] K. Apriliya, A. Syaiful, and E. Nasrullah, "Sistem Pemantauan Suhu dan Kelembaban Inkubator Telur Melalui 
Jaringan Global System for Mobile Comunication Berbasis Short Message Service," Electr. - J. Rekayasa dan Teknol. Elektro, vol. 10, no. 3, 2016.

[5] M. B. Agung, Arduino For Beginners, vol. 2, no. 2. 2014.

[6] Atmel Corporation, ATmega328, vol. Rev. 8161C. 2009.

[7] G. Description and T. Applications, LM3520 Integrated White LED Driver with Organic LED Display Power Supply Integrated White LED Driver with Organic LED Display, no. September. 2005.

[8]

Http://www.farnell.com/datasheets/169 6751.pdf, "Arduino GSM Shield," pp. 1-8.

[9] M. A. Badruzzaman, "Simulator Saklar Otomatis Kipas Angin Menggunakan Sensor Suhu," 2010.

[10] S. I. Langi, J. O. Wuwung, and A. S. M. Lumenta, "Kipas Angin Otomatis Dengan Menggunakan Sensor Suhu," EJournal Tek. Elektro dan Komput., pp. 41-48, 2014.

[11] S. A. Nugroho, "Detektor Suhu Ruangan Dengan Tombol Pengatur Manual Berbasis Mikrokontroler At89S51," Seruni dan Komput. FTI UNSA 2013, vol. 2, no. 1, pp. 15-21, 2013.

[12] Z. R. Munggaran and U. M. Buana, "Rancang Bangun Kontrol Suhu dan Kelembaban Pada Sistem Distribusi Tenaga Listrik Kubikel 20kV," Universitas Jenderal Achmad Yani, 2016.

[13] D. Harsono, J. Sunardi, and D. Biantara, "Pemantauan Suhu Dengan Mikrokontroler Atmega8 Pada Jaringan Lokal," Sekol. Tinggi Teknol. Nukl. BATAN, vol. 1, no. November, p. 416, 2009. 